\title{
Immunosuppression and the immune response in transplantation
}

\author{
DAVID LUDWIN, MBBCH, FRCPC, FACP, FRCP, DIANNE ARLEN, BSC, MD,
} J DAVID RUSSELL, MD, MA, FRCPC

\begin{abstract}
D Ludwin, D ARLEN, JD Russell. Immunosuppression and the immune response in transplantation. Can J Infect Dis 1993;4(Suppl C):5C-10C.

OвJEcrives: To review the roles of allorecognition, transplant rejection, and immunosuppressive therapy in predisposing patients to viral infections. Data Sources: Computer and bibliography searches were used to identify relevant articles. Study Selection and Data Extraction: Both review and single articles were critically assessed with respect to data analysis and clinical relevance. Conclusions: Advances in our knowledge about the nature and regulation of the immune response has enhanced our understanding of the etiology of transplant rejection. Host factors and immunosuppressive therapy may both be important in modulating the immune response after transplantation. Viral infections in the post-transplant period occur not only as a consequence of the immunocompromised state, but viruses themselves may either augment immunosuppression or initiate rejection.
\end{abstract}

Key Words: Graft-versus-host disease, Immunosuppression, Infection, Rejection, Transplantation, Virus

\section{Immunosuppression et réponse immunitaire dans les cas de transplantation}

Oвлестіғs: Passer en revue le rôle de l'alloreconnaissance, du rejet d'organes et du traitement immunosuppresseur dans la prédisposition des patients aux infections virales. SouRce des DonNÉEs: Interrogation de banques informatisées et consultations bibliographiques afin d'identifier les articles pertinents. SéLEction DES ÉTUDES ET EXTRACTION DEs DonNées: Des articles de synthèse et des articles de fond ont été évalués pour ce qui est de l'analyse des données et de la pertinence clinique. Conclusions: Les progrès de la connaissance au sujet de la nature et de la régulation de la réponse immunitaire a amélioré notre compréhension de l'étiologie du rejet d'organe. Les facteurs liés à l'hôte et le traitement immunosuppresseur peuvent être importants dans la modulation de la réponse immunitaire après la transplantation. Les infections virales durant la période post-transplantation surviennent non seulement à cause d'un état immunocompromis, mais les virus eux-mêmes peuvent, soit aggraver l'immunosuppression ou amorcer le rejet. 
$\mathrm{O}$ ER THE PAST DECADE, NEW IMMUNOSUPRESSIVE REGImens and improved patient care have had a beneficial impact on clinical outcome after transplantation, yet patient morbidity and mortality are still adversely influenced by infective complications. The immunocompromised state is characterized by infection with unusual organisms, especially viruses, and affected patients can develop a variety of life threatening illnesses. Further success in preventing and treating such infections will likely depend on the development of more specific forms of immunosuppression, as well as on an understanding of the altered immune response in transplant recipients, and will have a profound impact on the management of many nontransplant diseases. In this review, several newer concepts of rejection and immunosuppressive therapy are discussed.

\section{ALLOANTIGEN RECOGNITION}

Rejection occurs as a result of the host's response to alloantigen. Both antigen recognition and transplant rejection are the subject of intensive investigation, and excellent reviews have recently been published (1-7). It has long been recognized that survival of allografts is significantly influenced by the genes of the major histocompatibility complex (MHC), which in humans is localized to the short arm of the sixth chromosome. Two classes of molecules encoded by these genes are largely responsible for the recognition of, and response to, antigen by $\mathrm{T}$ lymphocytes. Although these two classes of molecules differ in structure, they share many similarities in the way they function (2). Class I human leukocyte antigen (HLA) molecules have a chain derived from polymorphic heavy-chain glycoproteins, encoded by genes in the MHC, which bind noncovalently to beta2-microglobulin, whereas two glycoprotein chains form the class II MHC molecules, both of which are encoded in the MHC region. Class I molecules are constitutively expressed on nucleated cells. In contrast, class II molecules are only expressed on B lymphocytes and other antigen presenting cells (APC) such as macrophages, monocytes and dendritic cells, although their expression in many other tissues can be induced by various stimuli (eg, interferon-gamma).

Our understanding of the immune response has been significantly enhanced by the observation that the presentation of a processed foreign peptide fragment by an APC to the antigen receptor of the T cell is mediated by host MHC molecules. The peptide fragment is 'held' for presentation in the peptide binding groove of the MHC molecule, as elegantly demonstrated for class I molecules (8). Class II molecules are thought to function in a similar way. Successful recognition of antigen only occurs (ie, is 'restricted') when the antigen is presented by self-MHC molecules. This was initially demonstrated using virus-infected cells which are destroyed when the MHC molecule on both cytotoxic and infected cells are identical (9). Immune recognition is also restricted in that class I MHC molecules 'recognize' $\mathrm{CD}^{+} \mathrm{T}$ lymphocytes, whereas class II molecules associate with CD4 receptors $(10,11)$. Allorecognition probably occurs in a similar way, albeit with the foreign MHC molecules fulfilling the functions of both antigen and presenting MHC. It is not yet known whether there is an additional role during this process for thus far unidentified peptides, which could be processed MHC fragments, bound in the MHC peptide groove $(7,12,13)$. Although the mechanisms whereby $\mathrm{T}$ lymphocytes recognize alloantigen and peptide fragments are essentially the same, only a limited number of $\mathrm{T}$ lymphocytes respond to the presentation of a peptide fragment; in contrast, large numbers of $\mathrm{T}$ cells will respond to alloantigen, resulting in a much stronger response. It is likely that the manner in which alloantigen is presented, ie, as foreign MHC with or without bound peptide, may account for this difference. The $\mathrm{T}$ cell antigen receptor (TCR) plays a critical role in the response to antigen, and its ability to recognize diverse antigens occurs as a result of genetic rearrangements of the germline sequences of its alpha and beta chains, which are strikingly similar to immunoglobulin chains.

The interaction between antigen and TCR initiates a series of intracellular events $(2,14)$. Dynamic trans recognition and cis aggregation of several surface molecule pairs occur during contact between the APC (or allogeneic cell) and the T lymphocyte. The contact is initially weak, but the recruitment of several accessory molecules stabilizes the interaction, allowing further recognition of the MHC-antigen complex by the Tymphocyte. This results in the nonantigen-specific binding of either CD8-CD3 (cytotoxic/suppressor) or CD4-CD3 (helper/inducer) molecules to the TCR complex. Engagement of the TCR results in the activation or inhibition of several genes, and culminates in the effector function of the T lymphocyte. Many other cell surface molecules participate in this process, and may influence cell homing and adhesion, as well as integrin function. Several receptors, whose functions are not yet completely understood, have also been identified. The signals relayed by these receptors are integrated within the cell, and signal transduction and cell activation appropriately modified.

TCR engagement activates two signal transduction pathways: the phosphatidylinositol pathway and a tyrosine kinase pathway. There is also evidence that a calcium channel may participate in this process $(2,15)$. In the first pathway, TCR stimulation results in phospholipase C mediated production of inositol 1,4,5-triphosphate and diacylglycerol, which are the second messengers responsible for mobilization of cytoplasmic free calcium and activation of protein kinase C. The protein tyrosine kinase is responsible for the phosphorylation of several substrates. Cytoplasmic free calcium and protein kinase $\mathrm{C}$ are ultimately responsible for gene activation. 
Once cell activation has been set in motion, the process proceeds relatively autonomously, with cytokine genes and their products among the first to be activated. Interleukin-2 and its receptor are early products of TCR activation, and play a critical role in further $\mathrm{T}$ cell proliferation and effector function. Other cytokines, such as interferon-gamma and interleukins-3 to -6 also participate in this process. These cytokines influence macrophage, B cell, granulocyte and stem cell proliferation and function, and induce further expression of MHC molecules on inducible cells.

Despite the importance of the MHC in the immune response, the clinical relevance of HLA matching in renal transplantation remains controversial (16).

\section{REJECTION}

Modern concepts regarding rejection have developed from the original observation of Medawar and colleagues (17). The complex events that underlie clinical rejection are initiated even before alloantigen recognition has occurred, as nonspecific inflammation may result from the donor procurement and surgical procedures. These events include surgical trauma, ischemia and drug toxicity $(18,19)$. The resulting inflammation, mediated in part by granulocytes and cytokines, endanger the allograft not only by causing cellular damage, but also by enhancing the risk of rejection through cytokine-mediated up-regulation of cell receptor expression and potentiation of the stimulatory potency of donor dendritic cells. After surgical implantation, several events occur sequentially or simultaneously (3). These events can be conceived of as occurring either within the allograft itself (the 'peripheral' compartment) or external to the allograft, primarily within the lymph nodes, spleen and blood (the 'central' compartment). It has been demonstrated that allostimulation also occurs within the graft (20), although circulating donor dendritic cells, functioning as 'passenger leukocytes', may play a qualitatively more significant role in allorecognition and sensitization.

These dendritic cells, which constitutively express class I and II MHC molecules, are potent immunostimulatory APCs and relocate outside of the graft, initiating the alloantigen recognition process in local lymph nodes, spleen and blood. As a result, resting $\mathrm{T}$ lymphocytes are transformed in host lymphoid tissue and then circulate widely; when they encounter donor alloantigen APC, endothelial or tubular cells (in the case of the kidney) within the graft, they are restimulated. These events lead to further local cytokine (in particular interferon-gamma, as well as interleukins-1 through -6 and tumour necrosis factor), eicosanoid and adhesion molecule production.

Mediators released locally following antigen recognition by sensitized T cells play a crucial role in perpetuating and amplifying the inflammatory response within the allograft, thus permitting the remaining phases of rejection to occur (3). Lymphocyte proliferation, migration, recruitment and attachment to allograft endothelium and other sites, as well as alloantibody production, occur as a consequence of this effector phase. The net result of this process is tissue damage, due to both specific and nonspecific immune-mediated and inflammatory reactions. The allograft undergoing rejection is invaded by macrophages, T lymphocytes (of both $\mathrm{CD}^{+}$and $\mathrm{CD}^{+}$phenotypes), natural killer cells, and B lymphocytes, and the local production of cytotoxic cytokines can also be demonstrated.

Allografts vary in their immunostimulatory potency, and this is influenced by such factors as constitutive expression of MHC on tissues (especially vascular endothelium), vascularity, MHC and other histocompatibility genes, as well as intrinsic allograft lymphocyte populations.

Bone marrow recipients are threatened by a bidirectional process involving both allograft rejection (ie, host-versus-graft disease) as well as graft-versus-host disease (GVHD) (21). The former response usually results in graft failure, which carries a very poor prognosis. GVHD occurs when the graft containing immunologically competent cells is transplanted into an immunoincompetent host incapable of rejecting the graft, and where donor-recipient alloantigen mismatch results in allorecognition. Both host-versus-graft as well as GVHD may occur in the same patient, and the predominance of either response will depend mainly on the nature of the allograft. In addition to marrow transplantation, GVHD has been observed after fetal liver, small bowel or pancreas-spleen transplantation, transfusion of blood or various blood products to immunocompromised hosts, and materno-fetal engraftment (22). The afferent and effector pathways of allorecognition and allogeneic GVHD responses are similar to those of classical rejection (host-versus-graft disease), although the clinical syndromes are different. GVHD is mediated primarily by $\mathrm{CD}^{+}$and $\mathrm{CD}^{+} \mathrm{T}$ lymphocytes, as well as by natural killer cells. Acute GVHD occurs in 20 to $50 \%$ of bone marrow transplants involving HLAidentical sibling donor-recipient pairs, and up to $80 \%$ of HLA-mismatched donor-recipient pairs, and is more likely to occur when there is an HLA donor-recipient mismatch, an older recipient or when the donor has previously been pregnant. Skin, liver and gut are the primary targets of acute GVHD. Chronic GVHD is diagnosed in 25 to $50 \%$ of patients up to 15 months after grafting, and the symptoms may range from mild to life threatening. Many of the symptoms of chronic GVHD resemble those of collagen vascular diseases, and the clinical syndromes may include localized or generalized scleroderma-like skin damage, autoimmune-like hepatic dysfunction, Sjögren's-type eye, salivary gland, and oral mucosal involvement, as well as muscle, lung and joint disease.

In summary, post-transplant injury occurs as a result 
of immune activation, which can manifest as two major processes: host-versus-graft disease and GVHD. While each process can predominate in a given patient and allograft, the two processes can also coexist, influencing the ultimate clinical manifestations of immune injury.

\section{IMMUNOSUPPRESSION AND INFECTION}

Infections occur in the immunocompromised host as a result of partial or complete abrogation of the immune response. The vulnerability to infection is not always related to the intensity of the immunosuppressive regimen, and the term 'net immunosuppression' has been coined to describe a given patient's propensity for infective complications (23). Determinants of net immunosuppression include: the nature of the underlying host disease, such as uremia, diabetes mellitus, liver failure and malnutrition; abrogation of local skin and mucosal defence mechanisms; and immunosuppressive agents (23-25). This section focuses on the roles of immunosuppressive agents as well as viruses, which are capable of modifying the immune response.

Immunosuppressive agents: The successes of modern transplantation have resulted from advances in the use of immunosuppressive agents. Several new agents are currently being introduced into clinical trials (26-28). In general, the immunosuppressive agents can be classified depending upon where they affect the cell cycle, although each agent may have multiple effects on the immune response.

Rapamycin blocks the transduction of the interleukin-2/interleukin-2 receptor signal and has a profound effect on the immune response. Although it is a macrolide antibiotic, and thus similar to FK 506, its mechanism of action differs from the latter drug, and indeed, the two drugs are antagonistic in vivo.

Steroids and 15-deoxyspergualin block interleukin1 production, inhibit macrophage function, and have additional effects on cytotoxic T cells and B cells. Glucocorticoids inhibit early gene transcription through binding of glucocorticoid-induced receptors or proteins to DNA response elements $(2,26,29)$.

Cyclosporine is the mainstay of modern transplant therapy, and is similar to FK 506, which is being used increasingly for liver and even heart transplantation. Both drugs bind to cytoplasmic proteins (cyclophilin and FK-binding protein, respectively) which are cis trans prolyl isomerase enzymes. These drug-binding protein complexes then inhibit calcineurins, which are a series of calcium-dependent phosphatases that cleave phosphate from cytoplasmic nuclear factor of activated lymphocytes (30). This reaction would normally allow the cleaved nuclear factor to permeate the nucleus and enhance mRNA transcription of interleukin-2. The effect of cyclosporine and FK 506 is thus to inhibit cytokine production, especially interleukin-2, despite prior allorecognition. The recent observation that cyclosporine toxicity is HLA-DR related may also prove to be important in understanding the mechanism of action of this agent (31). Newer analogues of cyclosporine (eg, IMM-125) are being tested clinically because nephrotoxicity remains an important impediment to its optimal use.

Two classes of agents inhibit DNA synthesis and cell proliferation, thereby suppressing humoral and cellmediated immune responses. This is achieved by inhibiting the enzymes of either the purine pathway (mizorbine and RS-61443 as well as the older drug 6-mercaptopurine and its oral analogue azathioprine) or the de novo pyrimidine biosynthetic pathway (brequinar). Mizorbine, an imidazole nucleoside antibiotic, has been extensively studied in Japan and may eventually replace azathioprine, which is associated with hepatotoxicity and marrow suppression. RS-61443, derived from mycophenolic acid, acts synergistically with cyclosporine and is undergoing clinical trials. Both mizorbine and RS-61443 are more selective inhibitors of DNA synthesis than azathioprine, and block only the de novo and not the salvage pathways of purine synthesis. Brequinar (quinoline caboxylic acid) is an anticancer agent which inhibits the enzyme dihydro-orotate dehydrogenase, and may have an important therapeutic role because of significant synergism with cyclosporine (32).

Biological preparations, which include OKT3 (directed against the $\mathrm{T}$ lymphocyte $\mathrm{CD} 3$ receptor) and polyclonal antilymphoblast preparations, will likely be supplanted by less toxic and more effective 'humanized' monoclonal antibodies which target other T lymphocyte receptors (28).

Finally, notwithstanding the plethora of new agents being introduced, it is likely that optimal clinical practice will continue to depend on the judicious use of several agents simultaneously (32).

Tolerance: Tolerance induction has been the subject of intensive study, as it is hoped that success in this area will diminish many of the problems associated with long term immunosuppressive therapy. The goal of achieving true tolerance for transplant allografts, defined as a state of specific unresponsiveness to either a nominal antigen or an alloantigen, has remained an elusive one $(33,34)$. Tolerance has been achieved in experimental animals (35), but only demonstrated in a limited number of clinical situations (eg, using protocols which employ blood or bone marrow transfusions, or following total lymphoid irradiation). The mechanisms thought to be responsible for $\mathrm{T}$ cell tolerance (clonal deletion, clonal anergy, and active suppression of the immune response) $(35,36)$ may also provide insight into our understanding of autoimmune disorders.

\section{IMMUNOMODULATION BY INFECTIVE AGENTS}

Infections in the immunocompromised host may occur not only as a result of the state of 'net immunosuppression', but may also enhance it (23). Human im- 
munodeficiency virus-associated immunosuppression has provided abundant information regarding the mechanisms of virus-induced immunosuppression (37), and the role of viruses in transplant patients has also been extensively studied. Recent findings regarding the role of superantigens (so named because they stimulate a large fraction of $\mathrm{T}$ lymphocytes) derived from bacteria and viruses, may prove to be important in understanding some of the problems of the immunocompromised host (38). Many infective agents, however, potentiate rather than suppress the immune response and inflammation, and it has been postulated that virus-specific MHC-restricted T lymphocytes may also initiate allograft rejection (39).

Several observations regarding the mechanisms of viral-induced immunomodulation have been made, and further studies will be required to determine the significance of these findings. T lymphocyte receptors may function as virus receptors (MHC for Semliki Forest virus and possibly adenovirus, and CD4 for human immunodeficiency virus) $(37,40-42)$, and the mechanisms whereby herpesviruses modify transplantation

\section{REFERENCES}

1. Halloran PF, Cockfield SM, Madrenas J. The mediators of inflammation (Interleukin 1, interferon- $\gamma$, and tumor necrosis factor) and their relevance to rejection. Transplant Proc 1989;21:26-30.

2. Krensky AM, Weiss A, Crabtree G, Davis MM, Parham P. T-lymphocyte-antigen interactions in transplant rejection. N Engl J Med 1990;322:510-7.

3. Gruber SA. The case for local immunosuppression. Transplantation 1992;54:1-11.

4. Hall BM. Cells mediating allograft rejection. Transplantation 1991;51:1141-51.

5. Colvin RB. The pathogenesis of vascular rejection. Transplant Proc 1991;23:2052-5.

6. Tilney NL, Whitley WD, Diamond JR, Kupiec-Weglinski JW, Adams DH. Chronic rejection - An undefined conundrum. Transplantation 1991;52:389-98.

7. Bradley JA, Mowat AM, Bolton EM. Processed MHC class I alloantigen as the stimulus for $\mathrm{CD}^{+} \mathrm{T}$-cell dependent antibody-mediated graft rejection. Immunol Today 1992;13:434-8.

8. Bjorkman PJ, Saper MA, Samraoui B, Bennet WS, Strominger JL, Wiley DC. Structure of the human class I histocompatibility antigen, HLA-A2. Nature 1987;329:506-12.

9. Zinkernagel RM, Doherty PC. Restriction of in vitro T cell-mediated cytotoxicity in lymphocytic choriomeningitis within a syngeneic or semiallogeneic system. Nature 1974;248:701-2.

10. Konig R, Huang LY, Germain RN. MHC class II interaction with CD4 mediated by a region analogous to the MHC class I binding site for CD8. Nature 1992;356:796-8.

11. Cammarota G, Scheirie A, Takacs B, et al. Identification of a CD4 binding site on the $\beta 2$ domain of HLA-DR molecules. Nature 1992;356:799-801.

12. Benichou G, Takizawa PA, Olson CA, McMillan M, Sercarz EE. Donor major histocompatibility complex (MHC) peptides are presented by recipient MHC molecules during graft rejection. J Exp Med alloimmunity have been intensively studied $(43,44)$. Interleukin-10, a pleiotropic cytokine which inhibits cytokine production by T helper 1 cells, is remarkably homologous to the $\mathrm{BCRF}_{1}$ segment of the Epstein-Barr virus, although the significance of this finding is not known (45). A similar homology between minor lymphocyte stimulating genes, whose products function as superantigens, and viruses has been reported (46). Finally, viruses are capable of attacking organs directly, and may be important in causing allograft dysfunction (47).

\section{CONCLUSIONS}

Advances in our knowledge about the nature and regulation of the immune response has enhanced our understanding of the etiology of transplant rejection. Host factors and immunosuppressive therapy may both be important in modulating the immune response after transplantation. Viral infections in the post-transplant period occur not only as a consequence of the immunocompromised state, but viruses may either augment immunosuppression or initiate rejection, and have a significant effect on morbidity and mortality.

1992;175:305-8.

13. Marrack P, Kappler J. The T cell receptor. Science 1987:238:1073-9.

14. Arnaiz-Villena A, Timón M, Rodriguez-Gallego C, et al. Human T-cell activation deficiencies. Immunol Today 1992;13:259-65.

15. Weiss A, Desai D, Graber M, Picus J, Koretzky G. The regulation of $\mathrm{T}$-cell antigen receptor signal transduction function. Transplant Proc 1991:23:32-3.

16. Hunsicker LG, Held PJ. The role of HLA matching for cadaveric renal transplantation in the cyclosporine era. Semin Nephrol 1992;12:293-303.

17. Tilney NL, Kupiec-Weglinski JW. The biology of acute transplant rejection. Ann Surg 1991;214:98-106.

18. Weinberg JM. The cell biology of ischemic renal injury. Kidney Int 1991;39:476-500.

19. Linas SL, Whittenburg D, Parsons PE, Repine JE. Mild renal ischemia activates primed neutrophils to cause acute renal failure. Kidney Int 1992;42:610-6.

20. Forbes RDC, Parfrey NA, Gomersall M, Darden AG, Guttmann RD. Dendritic cell-lymphoid cell aggregation and major histocompatibility antigen expression during rat cardiac allograft rejection. J Exp Med 1986;164:1239.

21. Billingham RE. The biology of graft-versus-host reactions. Harvey Lect 1966:62:21.

22. Zaia JA, Forman S.J. Management of the bone marrow transplant recipient. In: Parillo JE, Masur H, eds. The Critically Ill Immunocompromised Patient: Diagnosis and Management. Rockville: Aspen, 1987:381-413.

23. Auchincloss H, Rubin RH. Clinical management of the critically ill renal transplant patient. In: Parillo JE, Masur H, eds. The Critically Ill Immunocompromised Patient: Diagnosis and Management. Rockville: Aspen, 1987:347-80.

24. Tolkoff-Rubin NE, Rubin RH. Uremia and host defenses. N Engl J Med 1990;322:770-2.

25. Rubin RH. The compromised host as sentinel chicken. N Engl 1987;317:1151-3.

26. First MR. Renal transplantation for the nephrologist: New immunosuppressive drugs. Am J Kidney Dis 1992;19:3-9. 
27. Morris RE. Immunopharmacology of new xenobiotic immunosuppressive molecules. Semin Nephrol 1992;12:304-14.

28. Norman DJ. Antilymphocyte antibodies in the treatment of allograft rejection: Targets, mechanisms of action, monitoring, and efficacy. Semin Nephrol 1992;12:315-24.

29. Luisi BF, Xu WX, Otwinowski Z, Freedman LP, Yamamoto KR, Sigler PB. Crystallographic analysis of the interaction of the glucocorticoid receptor with DNA. Nature 1991;352:497-505.

30. Clipstone NA, Crabtree GR. Identification of calcineurin as a key signalling enzyme in T-lymphocyte activation. Nature 1992;357:695-7.

31. Zlabinger GJ, Kudlacek S, Pohanka E, et al. Evidence that sensitivity to cyclosporine is influenced by the HLA-DR phenotype of kidney graft recipients. Transplantation 1992;53:758-62.

32. Kahan BD, Gibbons-Stubber S, Tejpal N, Chou TC. Prospects for synergistic immunosuppressive drug therapy in the coming decade. Transplant Proc 1992;24:1263-5.

33. Owen RD. Immunogenetic consequences of vascular anastomoses between bovine twins. Science 1945; 102:400-1.

34. Billingham RE, Brent L, Medawar PB. 'Actively acquired tolerance' of foreign cells. Nature 1953;172:603-6.

35. Waer M, Strober S. The goal of specific immunologic unresponsiveness in clinical kidney transplantation. Semin Nephrol 1992;12:325-31.

36. Sachs DH. Specific transplantation tolerance. N Engl J Med 1991;325:1240-2.

37. Fox CH, Cottler-Fox M. The pathobiology of HIV infection. Immunol Today 1992;13:353-6.

38. Drake CG, Kotzin BL. Superantigens: Biology, immunology, and potential role in disease. J Clin Immunol 1992;12:149-62.

39. Gaston JSH, Waer M. Virus-specific MHC-restricted T lymphocytes may initiate allograft rejection. Immunol Today 1985;6:237-9.

40. Jacobson S, Biddison WE. Major histocompatibility complex molecules as virus receptors. Immunol Today 1984;5:262-3.

41. Maudsley DJ, Pound JD. Modulation of MHC antigen expression by viruses and oncogenes. Immunol Today 1991;12:429-31.

42. Lippé R, Luke E, Kuah YT, Lomas C, Jefferies WA. Adenovirus infection inhibits the phosphorylation of major histocompatibility complex class I proteins. J Exp Med 1991;174:1159-66.

43. Del Val M, Hengel H, Häcker $H$, et al. Cytomegalovirus prevents antigen presentation by blocking the transport of peptide-loaded major histocompatibility complex class I molecules into the medial-Golgi compartment. J Exp Med 1992; 176:729-38.

44. Duncombe AS, Grundy JE, Oblakowski P, et al. Bone marrow transplant recipients have defective MHC-unrestricted cytotoxic responses against cytomegalovirus in comparison with Epstein Barr virus: The importance of target cell expression of Lymphocyte Function-Associated Antigen 1 (LFA1). Blood 1992;79:3059-66.

45. Howard M, O'Garra A, Ishida H, De Waal Malefyt R, De Vries J. Biological properties of interleukin 10. J Clin Immunol 1992;12:239-47.

46. Robey E, Urbain J. Tolerance and immune regulation. Immunol Today 1991;12:175-7.

47. Vas SI. Primary and secondary role of viruses in chronic renal failure. Kidney Int 1991;40(Suppl 35):S2-4. 


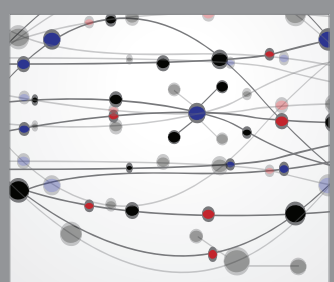

The Scientific World Journal
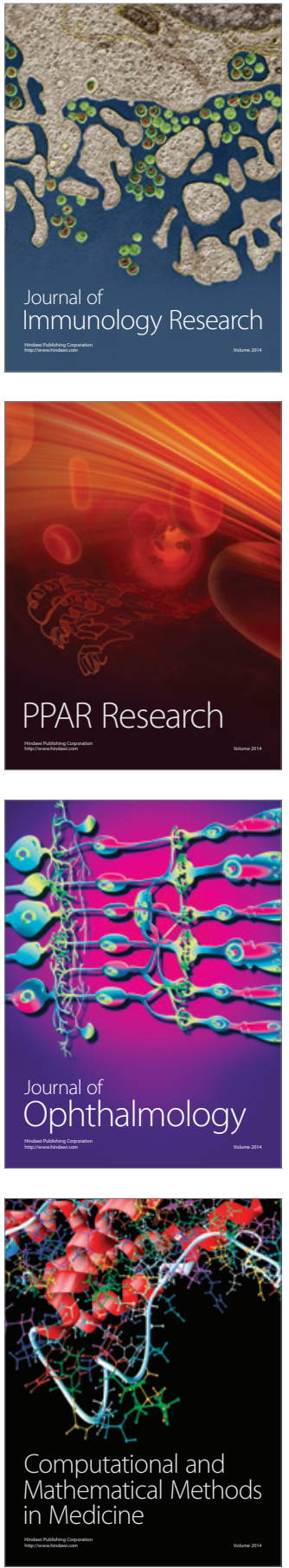

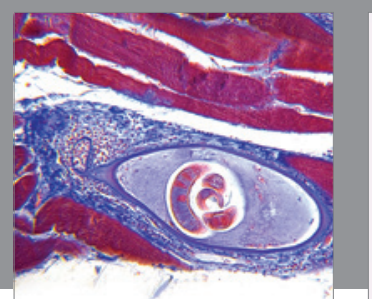

Gastroenterology Research and Practice

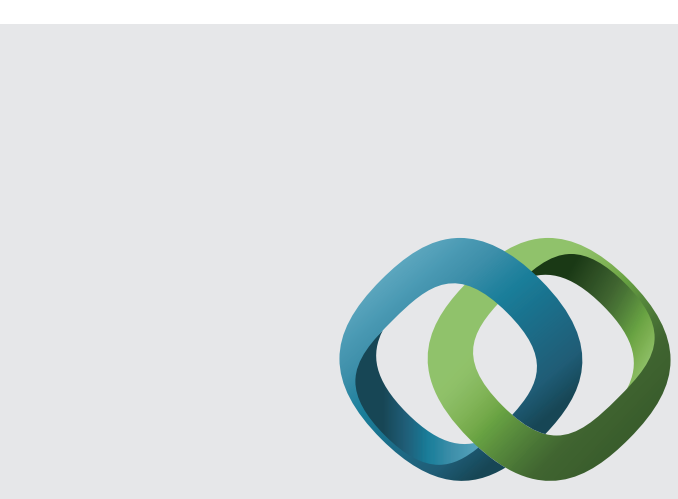

\section{Hindawi}

Submit your manuscripts at

http://www.hindawi.com
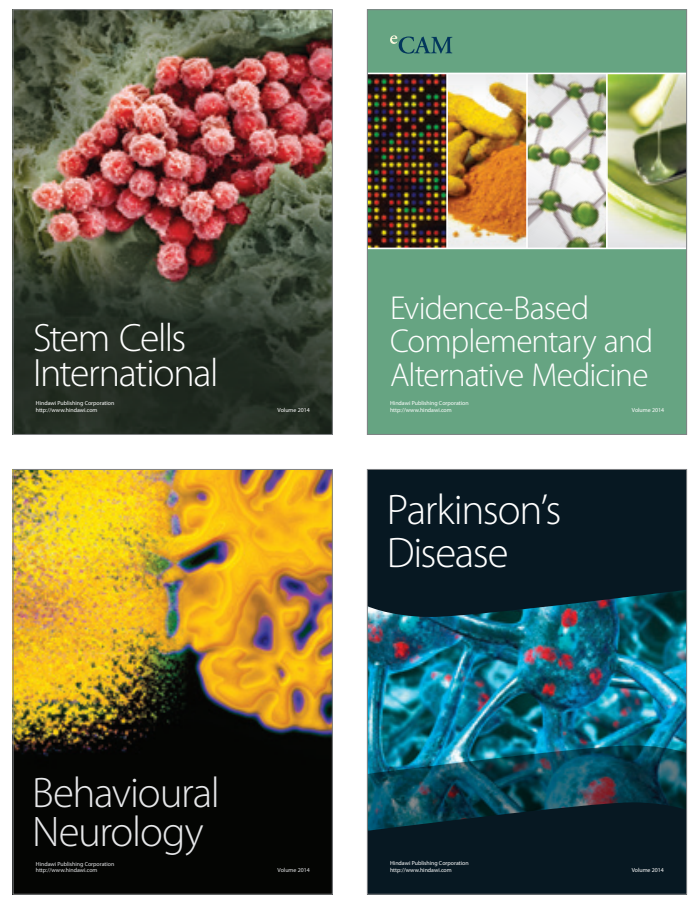
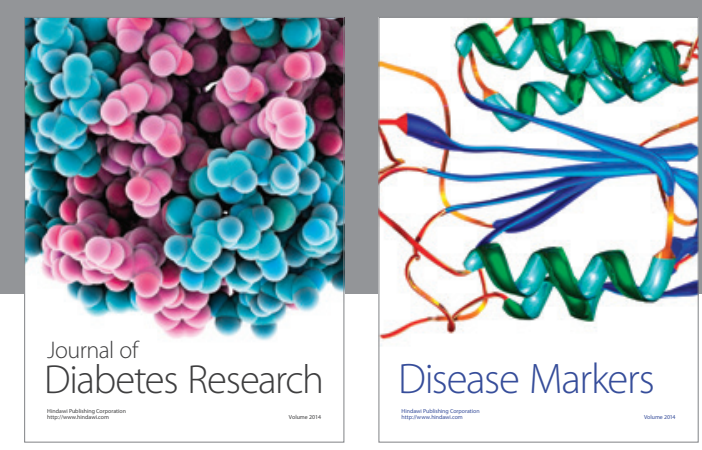

Disease Markers
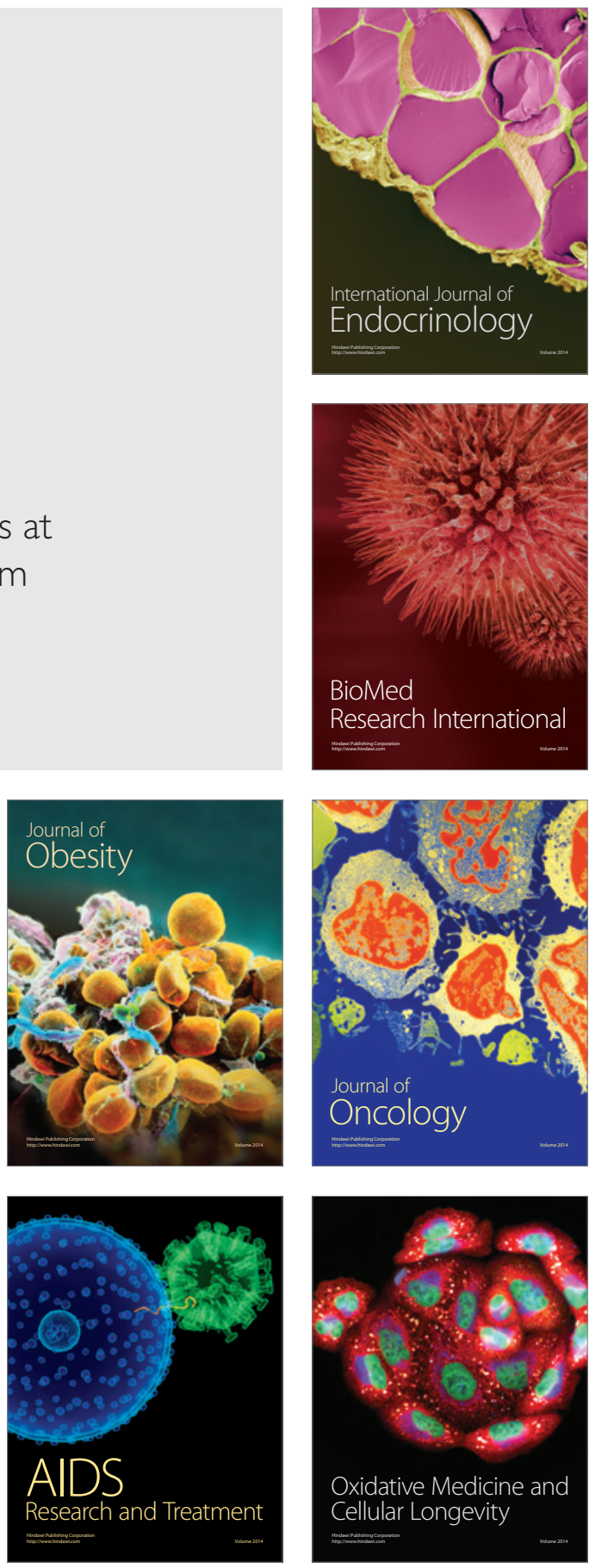